\title{
Proceeding
}

Asia Pacific Conference on Performance Analysis of Sport, 21-24 April 2014. Langkawi, Malaysia

\section{The effect of different systems of carrying backpacks on muscle activity}

\author{
HASSAN SAFIKHANI ${ }^{1}$, TENGKU FADILAH TENGKU KAMALDEN², SAIDON BIN AMRI², MEGAT \\ AHMAD M.M.H. ${ }^{3}$ \\ ${ }^{1}$ Department of Physical Education, Kermanshah Branch, Islamic Azad University, Kermanshah, Iran \\ 2 Department of Sport Studies, Faculty of Education Studies, UPM, Malaysia \\ ${ }^{3}$ Department of Mechanical and Manufacturing Engineering, UPNM, Malaysia
}

\begin{abstract}
Safikhani, H., Fadilah, T., Amri, S., \& Ahmad, M. (2015). The Effect of Different Systems of Carrying Backpacks on Muscle Activity. J. Hum. Sport Exerc., 9(Proc2), pp.S692-S698. Introduction: The purpose of this study is to compare the muscles activity in different systems of carrying the load in students and mountain climbers. EMG activity for TA and LD muscles were recorded with surface electrode while walking with different conditions. 26 young students attended three test sections in three days apart. After warm up subjects walked 10 min on the treadmill without backpack as a normal position in the first day. On the second day subjects walked 10 min with normal backpack, and on third day they walked 10 min with counterbalance load backpack. EMG activity of the TA and LD measured during three conditions of walking. One way analysis of variance (ANOVA) was applied on EMG patterns at muscles. The results indicated that there is a significant difference in TA and LD activities after walking with normal backpack and walking without backpack. There is an also significant difference in TA and LD activities between walking with normal backpack and counterbalance backpack. Results also indicated that there is no significant difference between walking without backpack and walking with counterbalance backpack with $p<.856$. Findings of this study clearly show the advantage of a counterbalance system for carrying the loads. In addition to these, the reduction of muscle activity is a considerable kinematic and ergonomic benefit of carrying load in such backpacks. Key Words: BACKPACK, COUNTERBALANCE, MUSCLE ACTIVITY.
\end{abstract}

Corresponding author. Islamic Azad University, Kermanshah, Iran

E-mail: safikhani2005@yahoo.com

Asia Pacific Conference on Performance Analysis of Sport, 21-24 April 2014. Langkawi, Malaysia.

JOURNAL OF HUMAN SPORT \& EXERCISE ISSN 1988-5202

(c) Faculty of Education. University of Alicante

doi:10.14198/jhse.2015.10.Proc2.08

VOLUME $10 \mid$ Proc 2 |2015| S692 


\section{INTRODUCTION}

A backpack is carrying equipment that is normally strapped on the back of the user for carrying a load. Backpacks are used every day by students, people young and old to transport items from place to place, but as helpful as they are, if used improperly they may cause back pain and injury to the user. When a backpack is overloaded, incorrectly worn, or improperly loaded it can cause a decrease in a person's performance. Students, military personnel, and athletes use various types of backpacks, and while carrying them in various ways they make adjustments to their posture to accommodate the load they are carrying. While the harmful effects of carrying heavy backpack loads have been realized and identified, what is important pertains to the potential long and short term health effects on adolescents who continue carrying backpacks (Goh et al., 1998).

The versatility of the backpack is seen in its popularity for various uses: in the military (Fergenbaum et al., 2008; Hadcock, 2002; Knapik et al., 2004; Reid et al., 2004; Stevenson et al., 2004), for recreation (Jacobson et al., 2000; Knight \& Caldwell, 2000), in industry (Abdoli-E et al., 2006; Van Vuuren et al., 2005), and a wide range of civilian use (Brackley \& Stevenson, 2004; Macias et al., 2005; Mackie et al., 2005; Rateau, 2004). Recent studies have shown that design features of backpacks and shoulder straps play a part in contributing to upper body injury (Fergenbaum, 2007). There is an urgent need to establish comprehensive safety guidelines for load carriage but before this can be done, various factors like the work environment, human pain threshold, backpack design, and distance traveled need to be reviewed.

Electromyography (EMG) is used to record activity of muscle during walking or running specially while carrying the load. Motmans et al. (2006) compared EMG activity from rectus abdominis and erector spinae muscles in five static modes. They didn't find significant differences in EMG activity between double back and unloaded standing during carried a load of $15 \%$ of their body weight. The results indicated that the EMG activity of erector spinae significantly decreased while carrying a backpack and increased with a front pack and shoulder bag. Al-Khabbaz et al. (2008) analyzed the activity of trunk-lower extremity muscles and trunk postural during the carriage of different backpacks. EMG activity from erector spinae, vastus medialis, rectus abdominis and biceps femoris muscle was recorded bilaterally. The results showed that the EMG activity of rectus abdominis muscle significantly increased progressively and disproportionably as the backpack load increased.

However, while there has been comprehensive research done by many researchers on the correlation of load and walking, there has been little done on the comparison of muscles activities during walking on level ground. It is believed that backpack and weight-related injuries can be significantly reduced by creating awareness among students, teachers, parents and mountain hikers of the importance of using backpacks and carrying loads properly in level walking. So this research intends study to assessment the EMG activity of TA and LD muscles during carrying different systems of backpacks.

\section{METHODS}

\section{Participants}

Twenty six (26) healthy male students (age: $22.41 \pm 1.75$ years old) participated in this research. Subjects were briefed on the use of backpack on a treadmill with different conditions of walking before participating in any testing. Participants were instructed to wear the same shoes for each trial, and to wear the shoes in which they would normally walk. 


\section{Experimental Protocol}

The subjects performed three conditions on three different days with the test order randomly assigned to prevent any test order effect. A 10 min warm-up was followed by gathering of some anthropometric data. On each testing day, each person after a 10 min warm-up performed one trial in the morning to walk under one of three different conditions. Participants were instructed to walk on the treadmill at a speed 1.5 meters/second. The first trial for all subjects was the unloaded walking condition for $10 \mathrm{~min}$. The second trial was walking with normal backpack for 10 min on the treadmill (Liu, 2007; Pal et al., 2009). Lastly all students walked 10 min on the treadmill with counterbalance load backpack after 10 min warm up. Tibialis anterior (TA) and latissimus dorsi (LD) muscle activities were measured during three conditions of walking on the treadmill.

TA and LD activity were selected for investigation. To determine muscle activation, surface EMG signals from these muscles were recorded from pre-gelled silver-silver/chloride bipolar surface electrodes (NORAXON INC USA). In this study as backpack load is a symmetrical carriage method, electrodes were only attached to one side (right) of the body. Electrode placement preparation and followed recommendations of SENIAM (Surface Electromyography for the Non-Invasive Assessment of Muscles) (Hermens, Freriks, Disselhorst-Klug \& Rau, 2000). For each muscle active were placed $2.5 \mathrm{~cm}$ parallel, apart with the alignment of the muscle fibers and secured with double-sided tape according to anatomic location of muscles as was described by Konard (2005). The external units were connected to the communications port of personal computer via an optical cable to gathering the data.

The amplitude (mV) of the EMG signal was collected on two muscles on right side of the subjects during walking with three conditions. Consequently, the normalized amplitudes were given as a percent of maximum amplitude for each participant, which allowed the researcher to identify changes in each participant regardless of individual differences in muscle strength.

\section{Statistical Analysis}

One way analysis of variance (ANOVA) was conducted on EMG patterns at TA and LD muscles with three conditions. If statistical significance was found between conditions a Tukey post-hoc test was used to examine where the differences exist within the conditions, where applicable. Mean differences approach with significance set at as $p<.05$.

\section{RESULTS}

The EMG raw amplitude for TA and LD muscles during walking on treadmill with different condition showed that the minimum activity was for unloaded walking, high activity was for walking with normal backpack. EMG activity decreased during walking with counterbalance loading (Table 1).

Table 1. Mean $( \pm S D)$ of TA and LD muscles activities after walking with different conditions

\begin{tabular}{cccc}
\hline $\mathrm{N}=26$ & & Mean $(\mathrm{mV})$ & $\begin{array}{c}\text { Std. } \\
\text { Deviation }\end{array}$ \\
\hline EMG TA & Without Backpack & .36 & .131 \\
& Normal Backpack & .68 & .11 \\
& Counterbalance Backpack & .37 & .13 \\
EMG LD & Without Backpack & .25 & .101 \\
& Normal Backpack & .59 & .103 \\
& Counterbalance Backpack & .27 & .104
\end{tabular}


The results indicated that there is a significant difference in TA activity after walking with normal backpack $(.68 \pm .11)$ and walking without backpack $(.36 \pm .131)$; there is also significant difference in TA activity between walking with normal backpack and counterbalance backpack (.37 .13). Within group analysis also indicated that there is no significant difference between walking without backpack and walking with counterbalance backpack with $p<.856$ (Tables 1 and 2).

The results for LD muscle showed there is a significant difference in LD activity after walking with normal backpack (.59 \pm .103$)$ and walking without backpack $(.25 \pm .101)$, and there is also significant difference in LD activity between walking with normal backpack and counterbalance backpack (.27士 .104). Within group analysis also indicated that there is no significant difference between walking without backpack and walking with counterbalance backpack with $p<.706$ (Tables 1 and 2).

In the Hoff test, the average initial lactate was $4.2 \pm 2.4 \mathrm{mmol} / \mathrm{L}$ and at the end of $12.4 \pm 3.8 \mathrm{mmol} / \mathrm{L}$, the maximum distance reached during the 10 minutes that the test lasts was $1597.6 \pm 143.2$ meters, with a maximum heart rate of $188.1 \pm 7.6$ beats per minute. The final data of the Hoff test and the progression of heart rate by the minute are found in Table 3 .

Table 2. Significant level of TA activity during walking without backpack, normal and counterbalance backpack

\begin{tabular}{|c|c|c|c|c|}
\hline $\begin{array}{l}\text { Dependent } \\
\text { Variable }\end{array}$ & (I) Condition & (J) Condition & $\begin{array}{c}\text { Mean Difference (I-J) } \\
(\mathrm{MV})\end{array}$ & Sig. \\
\hline \multirow{4}{*}{ EMG.TA } & Normal Backpack & Without Backpack & $.324^{*}$ & .000 \\
\hline & & $\begin{array}{c}\text { Counterbalance } \\
\text { Backpack }\end{array}$ & $.306^{*}$ & .000 \\
\hline & $\begin{array}{l}\text { Counterbalance } \\
\text { Backpack }\end{array}$ & Without Backpack & -.018 & .856 \\
\hline & & Normal Backpack & $-.306^{*}$ & .000 \\
\hline \multirow{4}{*}{ EMG.LD } & Normal Backpack & Without Backpack & $.342^{*}$ & .000 \\
\hline & & $\begin{array}{l}\text { Counterbalance } \\
\text { Backpack }\end{array}$ & $.319^{*}$ & .000 \\
\hline & $\begin{array}{l}\text { Counterbalance } \\
\text { Backpack }\end{array}$ & Without Backpack & -.022 & .706 \\
\hline & & Normal Backpack & $-.319^{*}$ & .000 \\
\hline
\end{tabular}

${ }^{\star}$ The mean difference is significant at the .05 level.

\section{DISCUSSION AND CONCLUSION}

The current study investigated which kind of backpack load affects the EMG activity of the TA and LD muscles. For these reasons, investigation of EMG activity during load carriage using a counterbalance backpack could provide insight into more effective load carrying methods.

Bobet and Norman (1984) investigated the EMG of trapezius and erector spine muscles during load carriage in backpack. Thomas and Donald (1987) also indicated that the EMG activity decreased in lumbar Para spinal muscles when a load was carried in backpack condition as compared with a load anterior to the chest carried by arms. After reviewing the muscle selection in previous investigations, TA and LD muscles were selected in this study. 
Finding of present study showed that higher activity was found when subjects used the normal backpack, muscle activity was also less while subjects walked on the treadmill with counterbalance backpack. If one backpack shows lower EMG activity than another backpack, then it may be less damaging on the carrier. (Figures 1 and 2).

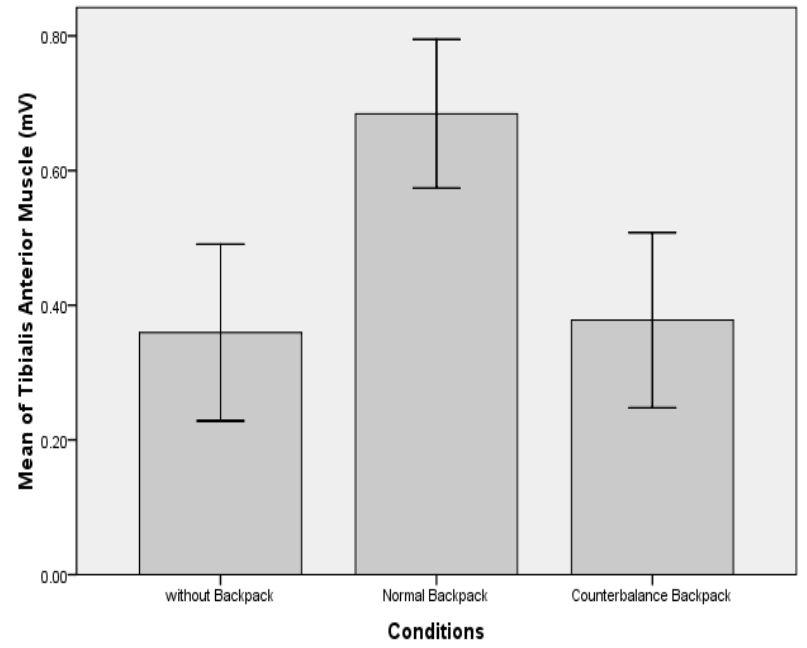

Figure1. Mean and SD of TA muscle activity after different conditions

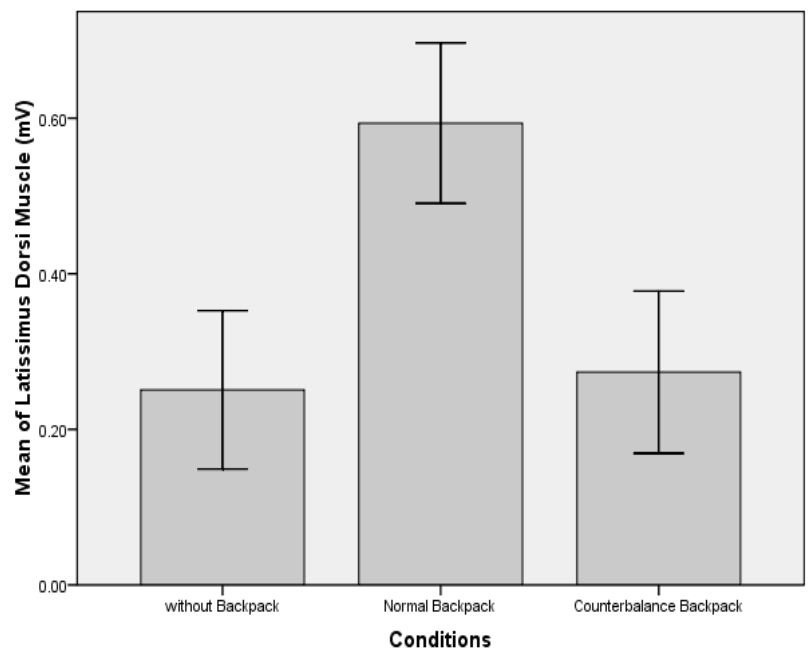

Figure 2. Mean and SD of LD muscle activity after different conditions

One could argue that it would be a more effective load carriage method, requiring less muscle activity for the same load. When walking with normal backpack, maybe increase the hip flexion and knee extension and help to shift the body forward and resist the gravitation. Walking with backpack increased muscle activation of LD and TA muscles might contribute to the difference between loading (normal backpack and counterbalance backpack) and unloading walking. The reduction of muscles activity is a considerable ergonomic and kinematic benefit of carrying load in such backpacks. Notwithstanding carrying a load may still be considered the major cause of changes to walking patterns or increases in injury rates, the scientific 
testing of and development of future counterbalance studies can modify these risks. Using a counterbalance backpack may be one such method to reduce these risks.

\section{REFERENCES}

1. Abdoli-E, M., Agnew, M., \& Stevenson, J. (2006). An on-body personal lift augmentation device (PLAD) reduces EMG amplitude of erector spinae during lifting tasks. Clinical Biomechanics, 21(5), pp.456-465.

2. Al-Khabbaz, Y.S.S.M., Shimada, T., \& Hasegawa, M. (2008). The effect of backpack heaviness on trunk-lower extremity muscle activities and trunk posture. Gait \& Posture, 28(2), pp.297-302.

3. Bobet, J., \& Norman, R.W. (1984). Effects of load placement on back muscle activity in load carriage. European Journal of Applied Physiology, 53(1), pp.71-75.

4. Brackley, H., \& Stevenson, J. (2004). Are Children's Backpack Weight Limits Enough? A Critical Review of the Relevant Literature. Spine, 29(19), pp.2184.

5. Fergenbaum, M., Hadcock, L., Stevenson, J., Bryant, J., Morin, E., \& Reid, S. (2008). Development of a Dynamic Biomechanical Model for Load Carriage: Phase IV Part C3: Dynamic Assessment of Pressure Measurement Systems for use in Human Load Carriage.

6. Goh, J., Thambyah, A., \& Bose, K. (1998). Effects of varying backpack loads on peak forces in the lumbosacral spine during walking. Clinical Biomechanics, 13(1S1), pp.26-31.

7. Hadcock, L. (2002). Factors affecting force distribution on a load carriage system waistbelt: UMI, Ann Arbor, Mich.

8. Hermens, H.J., Freriks, B., Disselhorst-Klug, C., \& Rau, G. (2000). Development of recommendations for SEMG sensors and sensor placement procedures. Journal of Electromyography and Kinesiology, 10(5), pp.361-374.

9. Jacobson, B., Wright, T., \& Dugan, B. (2000). Load carriage energy expenditure with and without hiking poles during inclined walking. International journal of sports medicine, 21(5), pp.356.

10. Knapik, J., Reynolds, K., \& Harman, E. (2004). Soldier load carriage: historical, physiological, biomechanical, and medical aspects. Military medicine, 169(1), pp.45-56.

11. Knight, C., \& Caldwell, G. (2000). Muscular and metabolic costs of uphill backpacking: are hiking poles beneficial? Medicine \& Science in Sports \& Exercise, 32(12), pp.2093.

12. Konrad, P. (2005). The ABC of EMG: a practical introduction to kinesiological electromyography. Scottsdale AZ Noraxon USA Inc.

13. Liu, B.S., \& Chou, H.T. (2004). Physiological responses during walking with combined dynamic and static loads. Paper presented at the 33rd international conference on computers and industrial engineering.

14. Macias, B., Murthy, G., Chambers, H., \& Hargens, A. (2005). High Contact Pressure Beneath Backpack Straps of Children Contributes to Pain. Archives of pediatrics \& adolescent medicine, 159(12), pp.1186.

15. Mackie, H., Stevenson, J., Reid, S., \& Legg, S. (2005). The effect of simulated school load carriage configurations on shoulder strap tension forces and shoulder interface pressure. Applied ergonomics, 36(2), pp.199-206.

16. Motmans, R., Tomlow, S., \& Vissers, D. (2006). Trunk muscle activity in different modes of carrying schoolbags. Ergonomics, 49(2), pp.127-138.

17. Pal, M. S., Majumdar, D., Bhattacharyya, M., \& Kumar, R. (2009). Optimum load for carriage by soldiers at two walking speeds on level ground. International Journal of Industrial Ergonomics, 39(1), pp.68-72. 
18. Rateau, M. (2004). Use of Backpacks in Children and Adolescents: A Potential Contributor of Back Pain. Orthopaedic Nursing, 23(2), pp.101.

19. Reid, S., Stevenson, J., \& Whiteside, R. (2004). Biomechanical assessment of lateral stiffness elements in the suspension system of a backpack. Ergonomics, 47(12), pp.1272-1281.

20. Stevenson, J., Bossi, L., Bryant, J., Reid, S., Pelot, R., \& Morin, E. (2004). A suite of objective biomechanical measurement tools for personal load carriage system assessment. Ergonomics, 47(11), pp.1160-1179.

21. Thomas, M., \& Donald, A.N. (1987). The effects of load placement on the EMG activity of the low back muscles during load carrying by men and women. Ergonomics, 30(10), pp.1413-1423.

22. Van Vuuren, B., Becker, P., Van Heerden, H., Zinzen, E., \& Meeusen, R. (2005). Lower back problems and occupational risk factors in a South African steel industry. American journal of industrial medicine, 47(5). 